\title{
Strong Convergence for Hybrid Implicit $S$-Iteration Scheme of Nonexpansive and Strongly Pseudocontractive Mappings
}

\author{
Shin Min Kang, ${ }^{1}$ Arif Rafiq, ${ }^{2}$ Faisal Ali, ${ }^{3}$ and Young Chel Kwun ${ }^{4}$ \\ ${ }^{1}$ Department of Mathematics and RINS, Gyeongsang National University, Jinju 660-701, Republic of Korea \\ ${ }^{2}$ Department of Mathematics, Lahore Leads University, Lahore 54810, Pakistan \\ ${ }^{3}$ Centre for Advanced Studies in Pure and Applied Mathematics, Bahauddin Zakariya University, Multan 60800, Pakistan \\ ${ }^{4}$ Department of Mathematics, Dong-A University, Busan 604-714, Republic of Korea
}

Correspondence should be addressed to Young Chel Kwun; yckwun@dau.ac.kr

Received 7 April 2014; Accepted 13 June 2014; Published 7 July 2014

Academic Editor: Abdul Latif

Copyright (C) 2014 Shin Min Kang et al. This is an open access article distributed under the Creative Commons Attribution License, which permits unrestricted use, distribution, and reproduction in any medium, provided the original work is properly cited.

Let $K$ be a nonempty closed convex subset of a real Banach space $E$, let $S: K \rightarrow K$ be nonexpansive, and let $T: K \rightarrow K$ be Lipschitz strongly pseudocontractive mappings such that $p \in F(S) \cap F(T)=\{x \in K: S x=T x=x\}$ and $\|x-S y\| \leq$ $\|S x-S y\|$ and $\|x-T y\| \leq\|T x-T y\|$ for all $x, y \in K$. Let $\left\{\beta_{n}\right\}$ be a sequence in $[0,1]$ satisfying (i) $\sum_{n=1}^{\infty} \beta_{n}=\infty$; (ii) $\lim _{n \rightarrow \infty} \beta_{n}=0$. For arbitrary $x_{0} \in K$, let $\left\{x_{n}\right\}$ be a sequence iteratively defined by $x_{n}=S y_{n}, y_{n}=\left(1-\beta_{n}\right) x_{n-1}+\beta_{n} T x_{n}, n \geq 1$. Then the sequence $\left\{x_{n}\right\}$ converges strongly to a common fixed point $p$ of $S$ and $T$.

\section{Introduction and Preliminaries}

Let $E$ be a real Banach space and let $K$ be a nonempty convex subset of $E$. Let $J$ denote the normalized duality mapping from $E$ to $2^{E^{*}}$ defined by

$$
J(x)=\left\{f^{*} \in E^{*}:\left\langle x, f^{*}\right\rangle=\|x\|^{2},\left\|f^{*}\right\|=\|x\|\right\}, \quad x \in E,
$$

where $E^{*}$ denotes the dual space of $E$ and $\langle\cdot, \cdot\rangle$ denotes the generalized duality pairing. We will denote the single-valued duality map by $j$.

Let $T: K \rightarrow K$ be a mapping.

Definition 1. The mapping $T$ is said to be Lipschitzian if there exists $L>1$ such that

$$
\|T x-T y\| \leq L\|x-y\|
$$

for all $x, y \in K$.

Definition 2. The mapping $T$ is said to be nonexpansive if

$$
\|T x-T y\| \leq\|x-y\|
$$

for all $x, y \in K$.
Definition 3. The mapping $T$ is said to be pseudocontractive if

$$
\|x-y\| \leq\|x-y+t((I-T) x-(I-T) y)\|
$$

for all $x, y \in K$ and $t>0$.

Remark 4. As a consequence of a result of Kato [1], it follows from the inequality that $T$ is pseudocontractive if and only if there exists $j(x-y) \in J(x-y)$ such that

$$
\langle T x-T y, j(x-y)\rangle \leq\|x-y\|^{2}
$$

for all $x, y \in K$.

Definition 5. The mapping $T$ is said to be strongly pseudocontractive if there exists a constant $t>1$ such that

$$
\|x-y\| \leq\|(1+r)(x-y)-r t(T x-T y)\|
$$

for all $x, y \in K$ and $r>0$. Or equivalently (see [2]) one has for $0<k<1$

$$
\langle T x-T y, j(x-y)\rangle \leq k\|x-y\|^{2}
$$

for all $x, y \in K$. 
For a nonempty convex subset $K$ of a normed space $E$, $T: K \rightarrow K$ is a mapping.

(I) The sequence $\left\{x_{n}\right\}$, defined by, for arbitrary $x_{1} \in K$,

$$
\begin{gathered}
x_{n+1}=\left(1-a_{n}\right) x_{n}+a_{n} T y_{n}, \\
y_{n}=\left(1-b_{n}\right) x_{n}+b_{n} T x_{n}, \quad n \geq 1,
\end{gathered}
$$

where $\left\{a_{n}\right\}$ and $\left\{b_{n}\right\}$ are sequences in $[0,1]$, is known as the Ishikawa iteration process [3].

If $b_{n}=0$ for $n \geq 1$, then the Ishikawa iteration scheme becomes the Mann iteration process [4].

$(S)$ The sequence $\left\{x_{n}\right\}$, defined by, for arbitrary $x_{1} \in K$,

$$
\begin{gathered}
x_{n+1}=T y_{n}, \\
y_{n}=\left(1-b_{n}\right) x_{n}+b_{n} T x_{n}, \quad n \geq 1,
\end{gathered}
$$

where $\left\{b_{n}\right\}$ is a sequence in $[0,1]$, is known as the $S$-iteration process $[5,6]$.

In the last few years or so, numerous papers have been published on the iterative approximation of fixed points of Lipschitz strongly pseudocontractive mappings using the Ishikawa iteration scheme (see, e.g., [3]). Results which had been known only in Hilbert spaces and only for Lipschitz mappings have been extended to more general Banach spaces (see, e.g., [7-13] and the references cited therein).

In 1974, Ishikawa [3] proved the following result.

Theorem 6. Let $K$ be a compact convex subset of a Hilbert space $H$ and let $T: K \rightarrow K$ be a Lipschitzian pseudocontractive mapping. For arbitrary $x_{1} \in K$, let $\left\{x_{n}\right\}$ be a sequence defined iteratively by

$$
\begin{gathered}
x_{n+1}=\left(1-\alpha_{n}\right) x_{n}+\alpha_{n} T y_{n}, \\
y_{n}=\left(1-\beta_{n}\right) x_{n}+\beta_{n} T x_{n}, \quad n \geq 1,
\end{gathered}
$$

where $\left\{\alpha_{n}\right\}$ and $\left\{\beta_{n}\right\}$ are sequences satisfying

(i) $0 \leq \alpha_{n} \leq \beta_{n}<1$;

(ii) $\lim _{n \rightarrow \infty} \beta_{n}=0$;

(iii) $\sum_{n=1}^{\infty} \alpha_{n} \beta_{n}=\infty$.

Then the sequence $\left\{x_{n}\right\}$ converges strongly to a fixed point of T.

In [7], Chidume extended the results of Schu [12] from Hilbert spaces to the much more general class of real Banach spaces and approximate the fixed points of pseudocontractive mappings. Also, in [14], he investigated the approximation of the fixed points of strongly pseudocontractive mappings.

In [15], Zhou and Jia gave the answer of the question raised by Chidume [14] and proved the following.

If $X$ is a real Banach space with a uniformly convex dual $X^{*}, K$ is a nonempty bounded closed convex subset of $X$, and $T: K \rightarrow K$ is a continuous strongly pseudocontractive mapping, then the Ishikawa iteration scheme converges strongly to the unique fixed point of $T$.

In [16], Liu et al. introduced the following condition.
Remark 7. Let $S, T: K \rightarrow K$ be two mappings. The mappings $S$ and $T$ are said to satisfy condition $(C 1)$ if

$$
\|x-T y\| \leq\|S x-T y\|
$$

for all $x, y \in K$.

In 2012, Kang et al. [17] established the strong convergence for the implicit $S$-iterative process associated with Lipschitzian hemicontractive mappings in Hilbert spaces.

Theorem 8. Let $K$ be a compact convex subset of a real Hilbert space $H$ and let $T: K \rightarrow K$ be a Lipschitzian hemicontractive mapping satisfying

$$
\|x-T y\| \leq\|T x-T y\|
$$

for all $x, y \in K$. Let $\left\{\beta_{n}\right\}$ be a sequence in $[0,1]$ satisfying

(i) $\sum_{n=1}^{\infty} \beta_{n}=\infty$;

(ii) $\sum_{n=1}^{\infty} \beta_{n}^{2}<\infty$.

For arbitrary $x_{0} \in K$, let $\left\{x_{n}\right\}$ be a sequence iteratively defined by

$$
\begin{gathered}
x_{n}=T y_{n}, \\
y_{n}=\left(1-\beta_{n}\right) x_{n-1}+\beta_{n} T x_{n}, \quad n \geq 1 .
\end{gathered}
$$

Then the sequence $\left\{x_{n}\right\}$ converges strongly to the fixed point $x^{*}$ of $T$.

In 2013, Kang et al. [18] proved the following result.

Theorem 9. Let $K$ be a nonempty closed convex subset of a real Banach space $E$, let $S: K \rightarrow K$ be a nonexpansive mapping, and let $T: K \rightarrow K$ be a Lipschitz strongly pseudocontractive mapping such that $p \in F(S) \cap F(T)=\{x \in K: S x=T x=x\}$ and

$$
\|x-S y\| \leq\|S x-S y\|, \quad\|x-T y\| \leq\|T x-T y\|
$$

for all $x, y \in K$. Let $\left\{\beta_{n}\right\}$ be a sequence in $[0,1]$ satisfying

(i) $\sum_{n=1}^{\infty} \beta_{n}=\infty$;

(ii) $\lim _{n \rightarrow \infty} \beta_{n}=0$.

For arbitrary $x_{1} \in K$, let $\left\{x_{n}\right\}$ be a sequence iteratively defined by

$$
\begin{gathered}
x_{n+1}=S y_{n} \\
y_{n}=\left(1-\beta_{n}\right) x_{n}+\beta_{n} T x_{n}, \quad n \geq 1 .
\end{gathered}
$$

Then the sequence $\left\{x_{n}\right\}$ converges strongly to a common fixed point $p$ of $S$ and $T$.

Keeping in view the importance of the implicit iteration schemes (see [17]) in this paper we establish the strong convergence theorem for the hybrid implicit $S$-iterative scheme associated with nonexpansive and Lipschitz strongly pseudocontractive mappings in real Banach spaces. 


\section{Main Results}

We will need the following results.

Lemma 10 (see $[19,20])$. Let $J: E \rightarrow 2^{E^{*}}$ be the normalized duality mapping. Then for any $x, y \in E$, one has

$$
\begin{array}{r}
\|x+y\|^{2} \leq\|x\|^{2}+2\langle y, j(x+y)\rangle, \\
\forall j(x+y) \in J(x+y) .
\end{array}
$$

Lemma 11 (see [13]). Let $\left\{\rho_{n}\right\}$ and $\left\{\theta_{n}\right\}$ be nonnegative sequences satisfying

$$
\rho_{n+1} \leq\left(1-\theta_{n}\right) \rho_{n}+b_{n}
$$

where $\theta_{n} \in[0,1), \sum_{n=1}^{\infty} \theta_{n}=\infty$, and $b_{n}=o\left(\theta_{n}\right)$. Then $\lim _{n \rightarrow \infty} \rho_{n}=0$.

The following is our main result.

Theorem 12. Let $K$ be a nonempty closed convex subset of a real Banach space $E$, let $S: K \rightarrow K$ be a nonexpansive mapping, and let $T: K \rightarrow K$ be a Lipschitz strongly pseudocontractive mapping such that $p \in F(S) \cap F(T)=\{x \in$ $K: S x=T x=x\}$ and condition (C3).

Let $\left\{\beta_{n}\right\}$ be a sequence in $[0,1]$ satisfying

(i) $\sum_{n=1}^{\infty} \beta_{n}=\infty$;

(ii) $\lim _{n \rightarrow \infty} \beta_{n}=0$.

For arbitrary $x_{0} \in K$, let $\left\{x_{n}\right\}$ be a sequence iteratively defined by

$$
\begin{gathered}
x_{n}=S y_{n}, \\
y_{n}=\left(1-\beta_{n}\right) x_{n-1}+\beta_{n} T x_{n}, \quad n \geq 1 .
\end{gathered}
$$

Then the sequence $\left\{x_{n}\right\}$ converges strongly to a common fixed point $p$ of $S$ and $T$.

Proof. For strongly pseudocontractive mappings, the existence of a fixed point follows from Deimling [21]. It is shown in [15] that the set of fixed points for strongly pseudocontractions is a singleton.

By (ii), since $\lim _{n \rightarrow \infty} \beta_{n}=0$, there exists $n_{0} \in \mathbb{N}$ such that $\forall n \geq n_{0}$,

$$
\beta_{n} \leq \min \left\{\frac{1}{4 k}, \frac{1-k}{2(1+L)(1+2 L)}\right\},
$$

where $k<1 / 2$ and $L$ is a Lipschitz constant of $T$. Consider

$$
\begin{aligned}
\| x_{n}- & p \|^{2} \\
& =\left\langle x_{n}-p, j\left(x_{n}-p\right)\right\rangle \\
& =\left\langle S y_{n}-p, j\left(x_{n}-p\right)\right\rangle \\
& =\left\langle T x_{n}-p, j\left(x_{n}-p\right)\right\rangle+\left\langle S y_{n}-T x_{n}, j\left(x_{n}-p\right)\right\rangle \\
& \leq k\left\|x_{n}-p\right\|^{2}+\left\|S y_{n}-T x_{n}\right\|\left\|x_{n}-p\right\|,
\end{aligned}
$$

where

$$
\begin{aligned}
\| S y_{n} & -T x_{n} \| \\
& \leq\left\|S y_{n}-T y_{n}\right\|+\left\|T y_{n}-T x_{n}\right\| \\
& \leq\left\|x_{n}-S y_{n}\right\|+\left\|x_{n}-T y_{n}\right\|+\left\|T y_{n}-T x_{n}\right\| \\
& \leq\left\|S x_{n}-S y_{n}\right\|+\left\|T x_{n}-T y_{n}\right\|+\left\|T y_{n}-T x_{n}\right\| \\
& =\left\|S x_{n}-S y_{n}\right\|+2\left\|T x_{n}-T y_{n}\right\| \\
& \leq(1+2 L)\left\|x_{n}-y_{n}\right\|,
\end{aligned}
$$

$$
\begin{aligned}
\left\|x_{n}-y_{n}\right\| & \leq\left\|x_{n}-x_{n-1}\right\|+\left\|x_{n-1}-y_{n}\right\| \\
& =\left\|S y_{n}-x_{n-1}\right\|+\left\|x_{n-1}-y_{n}\right\| \\
& \leq\left\|S x_{n-1}-S y_{n}\right\|+\left\|x_{n-1}-y_{n}\right\| \\
& \leq 2\left\|x_{n-1}-y_{n}\right\| \\
& =2 \beta_{n}\left\|x_{n-1}-T x_{n}\right\| \\
& \leq 2 \beta_{n}\left(\left\|x_{n-1}-p\right\|+\left\|p-T x_{n}\right\|\right) \\
& \leq 2 \beta_{n}\left(\left\|x_{n-1}-p\right\|+L\left\|x_{n}-p\right\|\right),
\end{aligned}
$$

and consequently from (18) and (19), we obtain

$$
\begin{aligned}
\left\|S y_{n}-T x_{n}\right\| \leq & 2(1+2 L) \beta_{n}\left\|x_{n-1}-p\right\| \\
& +2 L(1+2 L) \beta_{n}\left\|x_{n}-p\right\| .
\end{aligned}
$$

Substituting (20) in (17) and using (16), we get

$$
\begin{aligned}
\left\|x_{n}-p\right\| & \leq \frac{2(1+2 L) \beta_{n}}{1-k-2 L(1+2 L) \beta_{n}}\left\|x_{n-1}-p\right\| \\
& \leq\left\|x_{n-1}-p\right\| \quad \text { for } n \geq n_{0} .
\end{aligned}
$$

So, from the above discussion, we can conclude that the sequence $\left\{x_{n}-p\right\}$ is bounded. Since $T$ is Lipschitzian, so $\left\{T x_{n}-p\right\}$ is also bounded. Let $M_{1}=\sup _{n \geq 1}\left\|x_{n}-p\right\|+$ $\sup _{n \geq 1}\left\|T x_{n}-p\right\|$. Also by (ii), we have

$$
\begin{aligned}
\left\|x_{n-1}-y_{n}\right\| & =\beta_{n}\left\|x_{n-1}-T x_{n}\right\| \\
& \leq M_{1} \beta_{n} \\
& \longrightarrow 0
\end{aligned}
$$

as $n \rightarrow \infty$, which implies that $\left\{x_{n-1}-y_{n}\right\}$ is bounded, so let $M_{2}=\sup _{n \geq 1}\left\|x_{n-1}-y_{n}\right\|+M_{1}$. Further

$$
\begin{aligned}
\left\|y_{n}-p\right\| & \leq\left\|y_{n}-x_{n-1}\right\|+\left\|x_{n-1}-p\right\| \\
& \leq M_{2},
\end{aligned}
$$

which implies that $\left\{y_{n}-p\right\}$ is bounded. Therefore $\left\{T y_{n}-p\right\}$ is also bounded. 
Set

$$
M_{3}=\sup _{n \geq 1}\left\|y_{n}-p\right\|+\sup _{n \geq 1}\left\|T y_{n}-p\right\|
$$

Denote $M=M_{1}+M_{2}+M_{3}$. Obviously $M<\infty$. Now, from (15), for all $n \geq 1$, we obtain

$$
\left\|x_{n}-p\right\|^{2}=\left\|S y_{n}-p\right\|^{2} \leq\left\|y_{n}-p\right\|^{2},
$$

and by Lemma 10,

$$
\begin{aligned}
&\left\|y_{n}-p\right\|^{2} \\
&=\left\|\left(1-\beta_{n}\right) x_{n-1}+\beta_{n} T x_{n}-p\right\|^{2} \\
&=\left\|\left(1-\beta_{n}\right)\left(x_{n-1}-p\right)+\beta_{n}\left(T x_{n}-p\right)\right\|^{2} \\
& \leq\left(1-\beta_{n}\right)^{2}\left\|x_{n-1}-p\right\|^{2}+2 \beta_{n}\left\langle T x_{n}-p, j\left(y_{n}-p\right)\right\rangle \\
&=\left(1-\beta_{n}\right)^{2}\left\|x_{n-1}-p\right\|^{2}+2 \beta_{n}\left\langle T y_{n}-p, j\left(y_{n}-p\right)\right\rangle \\
&+2 \beta_{n}\left\langle T x_{n}-T y_{n}, j\left(y_{n}-p\right)\right\rangle \\
& \leq\left(1-\beta_{n}\right)^{2}\left\|x_{n-1}-p\right\|^{2}+2 k \beta_{n}\left\|y_{n}-p\right\|^{2} \\
&+2 \beta_{n}\left\|T x_{n}-T y_{n}\right\|\left\|y_{n}-p\right\| \\
& \leq\left(1-\beta_{n}\right)^{2}\left\|x_{n-1}-p\right\|^{2}+2 k \beta_{n}\left\|y_{n}-p\right\|^{2} \\
&+2 M L \beta_{n}\left\|x_{n}-y_{n}\right\|, \quad \forall j\left(y_{n}-p\right) \in J\left(y_{n}-p\right),
\end{aligned}
$$

which implies that

$$
\begin{aligned}
& \left\|y_{n}-p\right\|^{2} \\
& \leq \frac{\left(1-\beta_{n}\right)^{2}}{1-2 k \beta_{n}}\left\|x_{n-1}-p\right\|^{2}+\frac{2 M L \beta_{n}}{1-2 k \beta_{n}}\left\|x_{n}-y_{n}\right\| \\
& \leq\left(1-\beta_{n}\right)\left\|x_{n-1}-p\right\|^{2}+4 M L \beta_{n}\left\|x_{n}-y_{n}\right\| \quad \text { for } n \geq n_{0} .
\end{aligned}
$$

Because of (16), we have $\left(1-\beta_{n}\right) /\left(1-2 k \beta_{n}\right) \leq 1$ and $1 /(1-$ $\left.2 k \beta_{n}\right) \leq 2$. Also, by (ii) and (19), $\left\|x_{n}-y_{n}\right\| \leq 2 M(1+L) \beta_{n} \rightarrow 0$ as $n \rightarrow \infty$.

Hence (25) and (27) give

$$
\left\|x_{n}-p\right\|^{2} \leq\left(1-\beta_{n}\right)\left\|x_{n-1}-p\right\|^{2}+4 M L \beta_{n}\left\|x_{n}-y_{n}\right\| .
$$

For all $n \geq 1$, put

$$
\begin{aligned}
& \rho_{n}=\left\|x_{n-1}-p\right\|, \\
& \theta_{n}=\beta_{n}, \\
& b_{n}=4 M L \beta_{n}\left\|x_{n}-y_{n}\right\| ;
\end{aligned}
$$

then according to Lemma 11, we obtain from (28) that

$$
\lim _{n \rightarrow \infty}\left\|x_{n}-p\right\|=0
$$

This completes the proof.
Corollary 13. Let $K$ be a nonempty closed convex subset of a real Hilbert space $H$, let $S: K \rightarrow K$ be a nonexpansive mapping, and let $T: K \rightarrow K$ be a Lipschitz strongly pseudocontractive mapping such that $p \in F(S) \cap F(T)=\{x \in$ $K: S x=T x=x\}$ and condition (C3). Let $\left\{\beta_{n}\right\}$ be a sequence in $[0,1]$ satisfying conditions ( $i$ ) and (ii) in Theorem 12.

For arbitrary $x_{0} \in K$, let $\left\{x_{n}\right\}$ be a sequence iteratively defined by (15). Then the sequence $\left\{x_{n}\right\}$ converges strongly to a common fixed point $p$ of $S$ and $T$.

Example 14. As a particular case, we may choose, for instance, $\beta_{n}=1 / n$.

Remark 15. (1) Condition (C2) is due to Kang et al. [17] and condition (C1) with $S=T$ becomes condition (C2).

(2) Condition (C3) is due to Kang et al. [18] and condition (C3) with $S=T$ becomes condition (C2).

\section{Conflict of Interests}

The authors declare that there is no conflict of interests regarding the publication of this paper.

\section{Acknowledgments}

The authors would like to thank the editor and all referees for their valuable comments and suggestions for improving the paper. This study was supported by research funds from Dong-A University.

\section{References}

[1] T. Kato, "Nonlinear semigroups and evolution equations," Journal of the Mathematical Society of Japan, vol. 19, pp. 508$520,1967$.

[2] J. Bogin, "On strict pseudocontractions and a fixed point theorem," Technion Preprint MT-29, Haifa, Israel, 1974.

[3] S. Ishikawa, "Fixed points by a new iteration method," Proceedings of the American Mathematical Society, vol. 44, pp. 147-150, 1974.

[4] W. R. Mann, "Mean value methods in iteration," Proceedings of the American Mathematical Society, vol. 4, pp. 506-510, 1953.

[5] D. R. Sahu, "Applications of the $S$-iteration process to constrained minimization problems and split feasibility problems," Fixed Point Theory, vol. 12, no. 1, pp. 187-204, 2011.

[6] D. R. Sahu and A. Petruşel, "Strong convergence of iterative methods by strictly pseudocontractive mappings in Banach spaces," Nonlinear Analysis: Theory, Methods \& Applications, vol. 74, no. 17, pp. 6012-6023, 2011.

[7] C. E. Chidume, "Iterative approximation of fixed points of Lipschitz pseudocontractive maps," Proceedings of the American Mathematical Society, vol. 129, no. 8, pp. 2245-2251, 2001.

[8] C. E. Chidume and C. Moore, "Fixed point iteration for pseudocontractive maps," Proceedings of the American Mathematical Society, vol. 127, no. 4, pp. 1163-1170, 1999.

[9] C. E. Chidume and H. Zegeye, "Approximate fixed point sequences and convergence theorems for Lipschitz pseudocontractive maps," Proceedings of the American Mathematical Society, vol. 132, no. 3, pp. 831-840, 2004. 
[10] T. Jitpeera and P. Kumam, "The shrinking projection method for common solutions of generalized mixed equilibrium problems and fixed point problems for strictly pseudocontractive mappings," Journal of Inequalities and Applications, vol. 2011, Article ID 840319, 25 pages, 2011.

[11] N. Onjai-Uea and P. Kumam, "Convergence theorems for generalized mixed equilibrium and variational inclusion problems of strict-pseudocontractive mappings," Bulletin of the Malaysian Mathematical Sciences Society, vol. 36, no. 4, pp. 1049-1070, 2013.

[12] J. Schu, "Approximating fixed points of Lipschitzian pseudocontractive mappings," Houston Journal of Mathematics, vol. 19, no. 1, pp. 107-115, 1993.

[13] X. Weng, "Fixed point iteration for local strictly pseudocontractive mapping," Proceedings of the American Mathematical Society, vol. 113, no. 3, pp. 727-731, 1991.

[14] C. E. Chidume, "Approximation of fixed points of strongly pseudocontractive mappings," Proceedings of the American Mathematical Society, vol. 120, no. 2, pp. 545-551, 1994.

[15] H. Zhou and Y. Jia, "Approximation of fixed points of strongly pseudocontractive maps without Lipschitz assumption," Proceedings of the American Mathematical Society, vol. 125, no. 6, pp. 1705-1709, 1997.

[16] Z. Liu, C. Feng, J. S. Ume, and S. M. Kang, "Weak and strong convergence for common fixed points of a pair of nonexpansive and asymptotically nonexpansive mappings," Taiwanese Journal of Mathematics, vol. 11, no. 1, pp. 27-42, 2007.

[17] S. M. Kang, A. Rafiq, and S. Lee, "Strong convergence of an implicit $S$-iterative process for Lipschitzian hemicontractive mappings," Abstract and Applied Analysis, vol. 2012, Article ID 804745, 7 pages, 2012.

[18] S. M. Kang, A. Rafiq, and Y. C. Kwun, "Strong convergence for hybrid S-iteration scheme," Journal of Applied Mathematics, vol. 2013, Article ID 705814, 4 pages, 2013.

[19] S. Chang, "Some problems and results in the study of nonlinear analysis," in Nonlinear Analysis, vol. 30, pp. 4197-4208.

[20] H. K. Xu, "Inequalities in Banach spaces with applications," Nonlinear Analysis, vol. 16, no. 12, pp. 1127-1138, 1991.

[21] K. Deimling, "Zeros of accretive operators," Manuscripta Mathematica, vol. 13, pp. 365-374, 1974. 


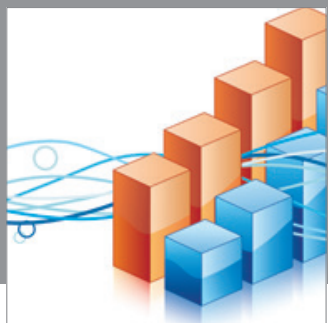

Advances in

Operations Research

mansans

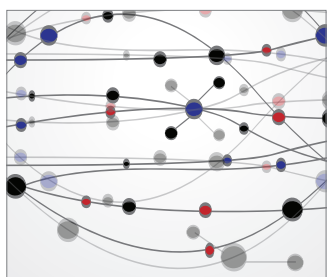

The Scientific World Journal
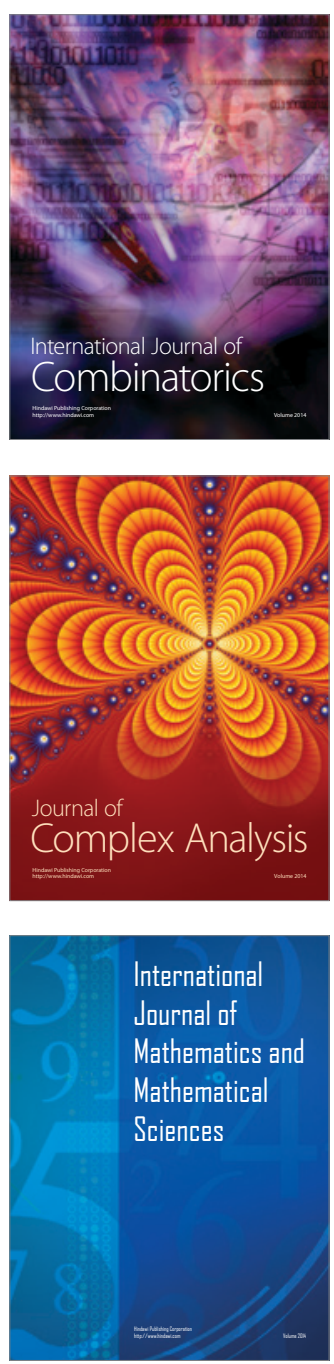
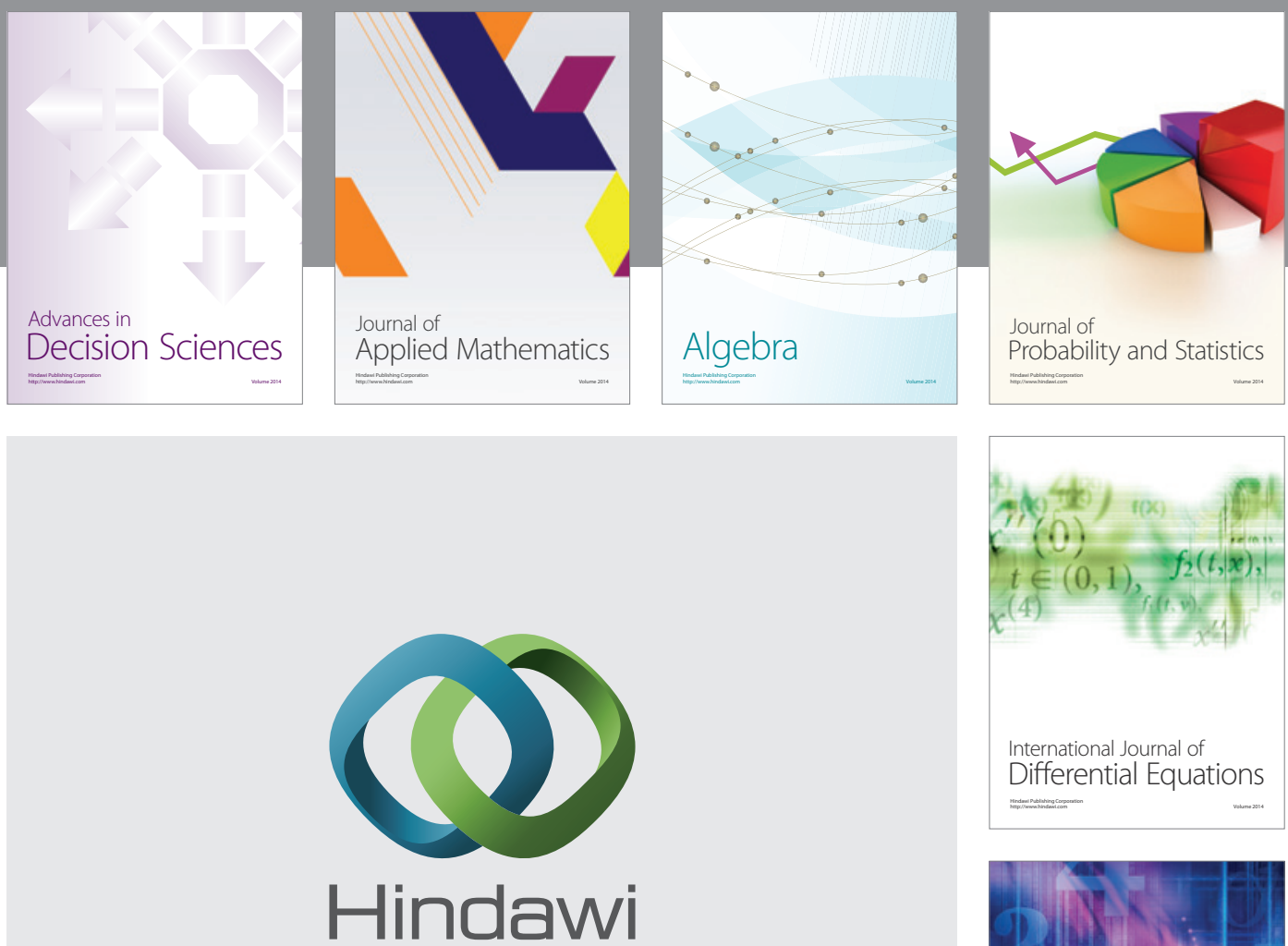

Submit your manuscripts at http://www.hindawi.com
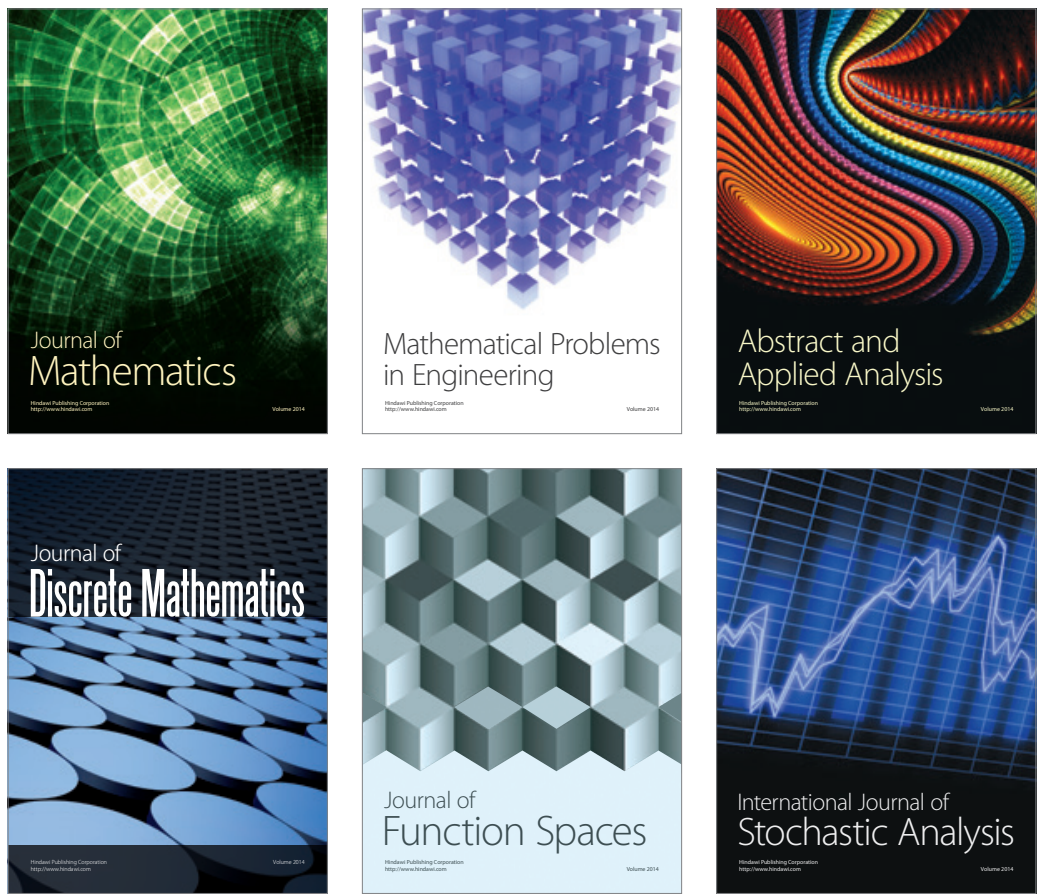

Journal of

Function Spaces

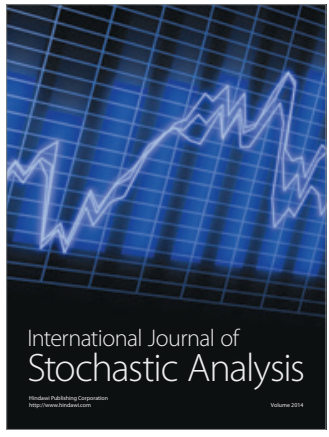

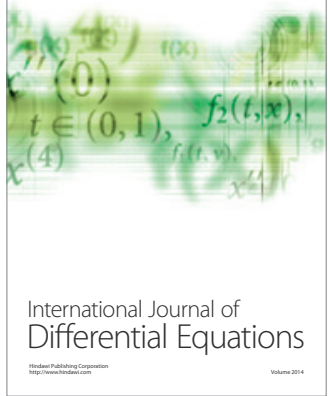
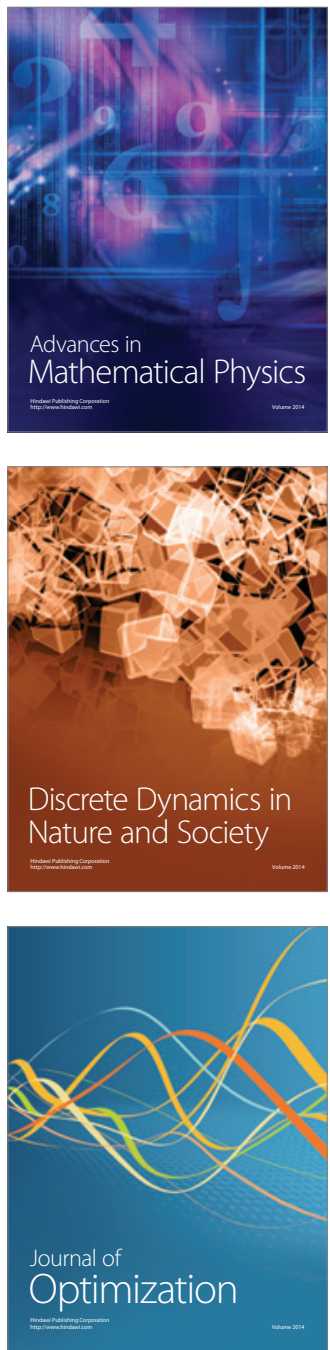